\title{
The role of TGF $\beta$ signaling in Gli1+ tendon and enthesis cells
}

\author{
Lee Song ${ }^{1}$
}

Mikhail Golman ${ }^{1,2}$

Adam C. Abraham ${ }^{3}$

Elazar Zelzer ${ }^{4}$

Stavros Thomopoulos ${ }^{1,2, *}$

${ }^{1}$ Department of Orthopedic Surgery, Columbia University, New York, NY10032, USA

2 Department of Biomedical Engineering, Columbia University, New York, NY10027, USA

${ }^{3}$ Department of Orthopaedic Surgery, University of Michigan, Ann Arbor, MI, 48109, USA

${ }^{4}$ Department of Molecular Genetics, Weizmann Institute of Science, Israel

* Correspondence: sat2@columbia.edu 


\begin{abstract}
The development of musculoskeletal tissues such as tendon, enthesis, and bone relies on proliferation and differentiation of mesenchymal progenitor cells. Gli1+ cells have been described as putative stem cells in several tissues and are presumed to play critical roles in tissue formation and maintenance. For example, the enthesis, a fibrocartilage tissue that connects tendon to bone, is mineralized postnatally by a pool of Gli1+ progenitor cells. These cells are regulated by hedgehog signaling, but it is unclear if TGF $\beta$ signaling, necessary for tenogenesis, also plays a role in their behavior. To examine the role of TGF $\beta$ signaling in Gli1+ cell function, the receptor for TGF $\beta$, TbR2, was deleted in Gli1-lineage cells in mice at P5. Decreased TGF $\beta$ signaling in these cells led to defects in enthesis formation by P56, including deficient bone morphometry underlying the enthesis and decreased mechanical properties. In vitro experiments using Gli1+ cells isolated from mouse tail tendons demonstrated that TGF $\beta$ controls cell differentiation and proliferation through canonical and non-canonical pathways and that TGF $\beta$ directly controls the tendon transcription factor Scx by binding to its distant enhancer. These results have implications in the development of treatments for tendon and enthesis pathologies.
\end{abstract}

Keywords: enthesis, Gli1, TGF $\beta$, TbR2, development 


\section{Introduction}

The musculoskeletal system is formed and maintained by a wide range of mesenchymal cells. Cells positive for Gli1, an essential hedgehog signaling transcription factor, have been described as putative stem cells in several tissues; a critical role for Gli1 + cells in development and response to injury has been shown for tendon, enthesis, teeth, bone, bone marrow, skin, colon, kidney, and heart [1-11]. These cells and their progenies have been localized to the tendon enthesis throughout postnatal development, eventually populating the entire fibrocartilage region between tendon and bone [12]. Furthermore, ablation of Gli1 + cells postnatally leads to a loss of mineralized fibrocartilage, suggesting that these cells play a critical role in enthesis mineralization [12]. Similarly, during tooth development, Gli1+ cells proliferate and differentiate into various cell types required for periodontal ligament and dental pulp formation [7, 8]. In bone, Gli1+ cells differentiate into various cell types at the growth plate during development and in the callus during fracture healing [10]. In tissues such as muscle, skin, and colon, Gli1+ cells have been reported to serve as stem cells within tissue-specific niches and actively regenerate injured tissues $[1,2,13]$. The regulation of these cells leading to their proliferation and/or differentiation is not fully understood, particularly for musculoskeletal tissues such as tendon and the enthesis.

Transforming growth factor beta (TGF $\beta$ ) is a pleiotropic cytokine that plays important roles in several cellular functions, including proliferation, differentiation, and extracellular matrix (ECM) synthesis [14]. TGF $\beta$ ligands work through the TGF $\beta$ receptors 1 and 2. Specifically, for the canonical pathway, a TGF $\beta$ ligand binds to the TGF $\beta$ receptor 2 (TbR2) and initiates a signaling cascade through Smad2/3. Alternatively, the noncanonical pathway results in activation of other factors such as MAPK and Akt [14, 15]. TGF $\beta$ signaling plays many critical roles in the formation of the musculoskeletal system. Deletion of TbR2 in Col2a-expressing cells resulted in smaller and disformed vertebral bones [16] and defects in the intervertebral disc (IVD) [17]; deletion in Col10a-expressing hypertrophic chondrocytes delayed bone collar calcification [18]; deletion in osteocalcin-expressing osteoblasts caused increased trabecular bone mass and decreased cortical bone mass [19]. Deletion of TbR2 in Prx1-expressing cells also severely impaired the formation of tendons and ligaments [20]. Similarly, deletion of TbR2 in scleraxis (Scx) expressing tendon cells led to severe tendon disruption and eventually death by P14. Further studies revealed that TGF $\beta$ signaling was necessary to maintain tendon cell phenotype via Scx expression [21]. Recently, deletion of TbR2 in Gli1 expressing periodontal ligament (PDL) progenitors was shown to reduce PDL cell numbers [22]. These prior studies point to a crucial role for TGF $\beta$ in the formation of tendon and the mineralization of the tendon enthesis.

It is unknown if TGF $\beta$ signaling regulates the behavior of Gli1+ cells in tendon and the enthesis. To examine the role of TGF $\beta$ signaling in these cells, we performed a series of in vivo and in vitro studies. TbR2 was deleted in Gli1+ cells at P5 using Gli1Cre ${ }^{\mathrm{ERT} 2} ; \mathrm{TbR} 2^{\mathrm{fl} / \mathrm{fl}}$ mice. To study the effect of this deletion on the development of the enthesis, the phenotype of rotator cuff entheses was examined using biomechanical, morphological, and histological assays. To study the effect of TbR2 deletion on Gli1+ tendon cells, cells were isolated from tail tendon and their in vitro behavior in response to TGF $\beta$ and hedgehog agonist stimulation was examined. Results revealed that TGF $\beta$ signaling is critical for the formation of a functional tendon enthesis and controls Gli1-lineage cells through canonical and noncanonical pathways.

\section{Materials and methods}

\section{Animal models}

To examine the effect of TGF $\beta$ signaling on tendon enthesis formation, TbR2 was deleted in Gli1+ cells at P5. The following mouse models were purchased from Jackson Laboratory (Bar Harbor, ME): Gli1Cre $^{\text {ERT2 }}$ (stock number 007913), TbR2 floxed (stock number 012603), mTmG (stock number 007676) and Ai14 (stock number 007914). To generate TbR2 deletion in Gli1-expressing cells, mice were crossed to produce Gli1Cre ${ }^{\mathrm{ERT} 2} ; \mathrm{TbR}^{\mathrm{fl} / \mathrm{fl}}$ conditional knockout (CKO) mice and Gli1Cre ${ }^{\mathrm{ERT} 2}$; TbR2 ${ }^{\mathrm{fl} / \mathrm{wt}}$ control mice 
(control). In order to label Gli1-lineage cells, Gli1Cre ${ }^{\text {ERT2}} ; \mathrm{TbR} 2^{\text {fl/fl }}$ mice were mated with mTmG reporter mice to generate Gli1Cre ${ }^{\text {ERT2}} ; \mathrm{TbR}^{\mathrm{fl} / \mathrm{llt}} ; \mathrm{mTmG}$ mice. In these mice, Gli1-expressing cells at the time of tamoxifen (TAM, Sigma-Aldrich, catalog number 06734) injection were labeled with membrane bound GFP while all the other cells were labeled with membrane bound td-Tomato [23]. To induce CreER nuclear localization and delete the TbR2 allele, mice were subjected to subcutaneous injection of TAM. TAM was dissolved in sterile corn oil (Sigma-Aldrich, catalog number: C8267) at a concentration of 10 $\mathrm{mg} / \mathrm{ml}$ and subcutaneously injected at $100 \mathrm{mg} / \mathrm{kg}$ body weight at P5 and P7 [12, 23]. Gli1Cre ${ }^{\text {ERT2}} ; \mathrm{TbR2}^{\mathrm{fl} / \mathrm{fl}}$ mice were used at 8 weeks of age. Due to the limitation of available mice, the control group for bone and mechanical property included both Gli1-Cre ${ }^{\mathrm{ERT}} ; \mathrm{TbR} 2^{\mathrm{fl} / \mathrm{wt}}$ and $\mathrm{TbR} 2^{\mathrm{fl} / \mathrm{fl}}$ mice since both strains express TbR2. All the mouse experiments were proved by Institutional Animal Care and Use Committee of Columbia University. The phenotypes of the mice were determined using biomechanics, bone morphometry, and histologic analyses.

Micro computed tomography (micro-CT)

Mice were euthanized at P56, humerus-supraspinatus tendon/muscle samples were isolated, and samples were stored in saline-soaked gauze at $-20^{\circ} \mathrm{C}$ until scanning ( $\mathrm{N}=14$ for control, $\mathrm{N}=11$ for $\mathrm{CKO}$ ). Specimens were thawed and $\mu C T$ scanning was performed using a Skyscan 1271 scanner (Bruker Corporation) at an energy of $60 \mathrm{kV}$, intensity of $166 \mu \mathrm{A}, 0.25 \mu \mathrm{m}$ aluminum filter, and $5 \mu \mathrm{m}$ resolution. Scanned images were evaluated using a custom segmentation algorithm to separate cortical and trabecular bones of the humeral head proximal to the growth plate (CTAn, Bruker Corporation). Bone mineral density (BMD) and total mineral density (TMD), bone volume fraction (BV/TV), trabecular number (Tb.N), trabecular thickness (Tb.Th), and trabecular spacing (Tb.Sp) were measured. Tendon crosssectional area was measured by thresholding $\mu \mathrm{CT}$ images of sagittal slices through the tendon. The minimum cross-sectional area was used for mechanical property analysis [24, 25].

\section{Biomechanical testing}

After $\mu$ CT scanning, the supraspinatus muscle was carefully scraped from the tendon, the humerus bone was mounted in a custom 3D printed fixture, and a uniaxial tensile test to failure was performed using an Electroforce 3230 testing frame (TA Instruments) ( $\mathrm{N}=14$ for control, $\mathrm{N}=11$ for $\mathrm{CKO}$ ) [26]. The testing protocol consisted of 5 cycles of preconditioning ( $2 \%$ strain, $0.2 \% / \mathrm{s}), 180 \mathrm{~s}$ recovery, and extension to failure at $0.2 \% / \mathrm{s}$. Strain was determined from grip-to-grip displacement relative to the initial gauge length. Stress was determined using the minimum cross-sectional area of the tendon, as determined from $\mu C T$. Structural properties were determined from load/deformation curves, including failure load (maximum load), stiffness (slope of linear portion of load/deformation curve), and work to failure (area under load/deformation curve through yield). Material properties were determined from stress/strain curves, including strength (maximum stress), modulus (slope of linear portion of stress/strain curve), and resilience (area under the curve through yield).

\section{Histology and immunohistochemistry}

Mice were euthanized at P16, humeral-supraspinatus tendon/muscle samples were isolated, and samples were fixed in 4\% paraformaldehyde (ThermoFisher Scientific, catalog number 50-980-487) at $4^{\circ} \mathrm{C}$ overnight ( $\mathrm{N}=8$ for control, $\mathrm{N}=3$ for $\mathrm{CKO}$ ). The specimens were then decalcified in $10 \%$ EDTA ( $\mathrm{pH}$ 7.4) (Poly Biotech). Specimens were then rinsed in PBS and placed in either in $30 \%$ sucrose (Fisher Scientific, catalog number S5-500) for frozen sectioning or $70 \%$ ethanol (Fisher Scientific, catalog number A4094) for paraffin sections. The specimens in sucrose were then embedded in OCT compound (VWR, catalog number 25608-930) and sectioned into $9 \mu \mathrm{m}$-thick sections using a cryostat (Ag protect, CM1860, Leica). The specimens in ethanol were embed in paraffin and sectioned into $5 \mu \mathrm{m}$-thick sections. The sections were then stained with either Vector Laboratories' hematoxylin/eosin (H\&E) (Fisher Scientific, catalog number NC1470670) or stained with Smad2 using immunohistochemistry. For Ki67 staining, the frozen sections were fixed in 10\% neutral buffered formalin (StatLab, catalog number 28600-1) for 20 minutes, and permeabilized in 1\% Triton X-100 (Sigma-Aldrich, catalog number T9284). After blocking with $5 \%$ bovine serum albumin (BSA, fraction V) (Fisher Scientific, catalog number BP1600), the sections were incubated with 1:250 anti Ki67 (Abcam, catalog number ab15580) over night at $4^{\circ} \mathrm{C}$. The sections were then incubated with 1:1000 anti rabbit IgG- Alexa Fluor 555 (Invitrogen, product number A27039) 
after washed 3 times with TBS-Tween 20 (TBST). The sections were then rinsed with TBST and mounted with VECTASHIELD Plus mounting media with DAPI (Vector Laboratory, reference number H-2000).

In vitro studies

To examine the role of TGF $\beta$ signaling in Gli1 + cell function, Gli1+ cells labeled with GFP were isolated from tail tendons and cultured, as previously described [27]. Briefly, tail tendon fascicles were peeled from their attachments, chopped into small pieces with a razor blade, and digested in $5 \mathrm{ml}$ of complete medium (MEMa [ThermoFisher Scientific, catalog number 12561072] containing 10\% fetal bovine serum [Gemini Bio-products], $100 \mathrm{U} / \mathrm{ml}$ penicillin-streptomycin [ThermoFisher Scientific, catalog number 15140122]) containing 4-5 mg/ml type II collagenase (Worthington Biochemical Corp, catalog number 004117 ) at $37^{\circ} \mathrm{C}$ with $225 \mathrm{rpm}$ shaking. After 1.5 hours, $5 \mathrm{ml}$ of complete medium was added to the digestion. The digested tendon fragments were then passed through a $20 \mathrm{G}$ needle to break any clumps and then filtered through a $70 \mathrm{~mm}$ cell trainer (Fisher Scientific, catalog number 08-771-2). The cells were then spun down at $350 \mathrm{xg}$ for $5 \mathrm{~min}$ and washed once with $5 \mathrm{ml}$ fresh complete medium. The cells were then re-suspended in $3 \mathrm{ml}$ of complete medium in a $35 \mathrm{~mm}$ cell culture plate until they reached $80 \%$ confluence. The cells were then lifted by trypsin/EDTA (ThermoFisher Scientific, catalog number 25200056) and re-plated at a 1:2 ratio. The cultured cells were separated by flow cytometry Influx (BD Bioscience) at passage 5 based on their expression of either GFP or td-tomato. The sorted cells were then further expanded. The cells were then replated at 3,000 $/ \mathrm{cm}^{2}$ and starved in MEMa with $1 \%$ FBS overnight. For Western blot analysis, the starved cells were then treated with $5 \mathrm{ng} / \mathrm{ml}$ of recombinant murine TGF $\beta 1$ (PEPROTECH, catalog number AF-100-21C). Cell responses were evaluated at 0,15, 30, 60, 120, and 1440 minutes. Cells were lysed with RIPA Lysis and Extraction Buffer (ThermoFisher Scientific, catalog number: 89900) supplemented with Halt ${ }^{\mathrm{TM}}$ Protease and Phosphatase Inhibitor Cocktail (ThermoFisher Scientific, catalog number 78440) according to manufacturer's instructions. For gene expression analysis, the starved cells were treated with recombinant murine TGF $\beta 1$ ( $5 \mathrm{ng} / \mathrm{ml})$ or hedgehog agonist (Hh-Ag1.5, Xcess Bioscicences Inc., CAS\# 612542-14-0, 0.1uM) for 1, 4, 24, 48, and 72 hours. Total RNA was extracted using RNeasy Mini Kit (Qiagen, catalog number:74104). For immunofluorescence, cells were grown on a cover slip and treated with recombinant TGF $\beta 1$ ( $5 \mathrm{ng} / \mathrm{ml})$ for 60 minutes.

\section{Western blot analysis}

Western blot analyses were performed on cultured Gli1+ cells to determine signaling pathways induced by TGF $\beta$ ( $\mathrm{N}=5$ cell isolations for control, $\mathrm{N}=3$ cell isolations for $\mathrm{CKO}$ ). Whole cell lysates were quantified with the Pierce ${ }^{T M}$ BCA Protein Assay Kit (ThermoFisher Scientific, catalog number: 20227). $20 \mu \mathrm{g}$ of total protein was separated on an $8 \%$ SDS-PAGE, transferred to a $0.2 \mu \mathrm{m}$ nitrocellulose membrane (BioRad, catalog number 1620112), and probed with anti-phospho-Smad2 (Cell Signaling Technology, catalog number 18338S; 1:1,000), anti-Smad2 (Cell Signaling Technology, catalog number 5339S; 1:1,000), anti phospho-cJun (Cell Signaling Techology, catalog number 3270S), anti cJun (Cell Signaling Technology, catalog number 9165S), anti-phospho-SAPK/JNK (Cell Signaling Technology, catalog number 4668S), anti JNK (Cell Signaling Technology, catalog number 9252S), anti-phospho-p38 MAPK (Cell Signaling Technology, catalog number 4511S), anti-p38 MAPK (Cell Signaling Technology, catalog number 8690S), anti-phospho-p44/p42 MAPK (pErk, Cell Signaling Technology, catalog number 8690S), anti-p44/p42 MAPK (Erk, Cell Signaling Technology, catalog number 4695S), and anti-GAPDH (Cell Signaling Technology, catalog number 5174S; $1: 1000)$. The primary antibody was detected with an anti-rabbit lgG, HRP-linked secondary antibody (Cell Signaling Technology, catalog number 7074S; 1:4,000) and visualized with either SuperSignalTM West Femto Maximum Sensitivity Substrate (ThermoFisher Scientific, catalog number 34094) or SuperSignal ${ }^{\mathrm{TM}}$ West Pico PLUS Chemiluminescent Substrate (ThermoFisher Scientific, catalog number 34577) for phospho-JNK and GAPDH. Images were taken with an Azure 600C Imager (Azure Biosystems). Between application of different antibodies, the nitrocellulose membrane was stripped with RestoreTM Western Blot Stripping Buffer (ThermoFisher Scientific, catalog number 21059) according to manufacturer's instructions.

Quantitative polymerase chain reaction ( $\mathrm{qPCR}$ ) 
To determine expression patterns of cells induced with TGF $\beta$, qPCR was performed on cultured Gli1+ cells ( $N=8$ cell isolations for control, $N=3$ cell isolations for $C K O)$. One hundred nanograms of total RNA were reversely transcribed into complementary DNA (cDNA) using Maxima First Strand cDNA Synthesis Kit for RT-qPCR (ThermoFisher Scientific, catalog number K1641). The cDNA was diluted 10-fold with water and $2 \mu \mathrm{L}$ of diluted cDNA was quantified for each specific gene using Power SYBR ${ }^{\mathrm{TM}}$ Green PCR Master Mix (ThermoFIsher Scientific, catalog number 4368706) in a QuantStudio ${ }^{\text {TM }} 6$ Pro Real-Time PCR System (ThermoFisher Scientific, catalog number: A44288) according to manufacturer's instructions. The primer pairs for each gene were designed using an online primer design tool (Primer3, http://primer3.ut.ee/). The primer sequences are listed in Table 1.

Table 1. Primer sequences for qPCR

\begin{tabular}{|l|l|l|}
\hline Gene & Forward primer & Reverse primer \\
\hline Scx & 5' ccaaacagatctgcaccttc & 5' tgtcacggtcttgctcaac \\
\hline Sox9 & 5' tgcagcacaagaaagaccac & 5' cgttcttcaccgacttcctc \\
\hline Gli1 & 5' tgtgtgagcaagaaggttgc & 5' atggcttctcattggagtgg \\
\hline GAPDH & 5' gcacagtcaaggccgagaat & 5' gccttctccatggtggtgaa \\
\hline
\end{tabular}

\section{Chromatin immunoprecipitation (ChIP)}

ChIP analysis was performed to explore how TGF $\beta$ controls expression of Scx, a key tendon enthesis transcription factor [28] ( $\mathrm{N}=2$ cell isolations for control and $\mathrm{N}=2$ cell isolations for $\mathrm{CKO}$ ). Tail tendon fibroblasts from control and CKO mice were grown to $90 \%$ confluence in $15 \mathrm{~cm}$ cell culture plates. The cells were treated with TGF $\beta 1(5 \mathrm{ng} / \mathrm{ml})$ for 1 hour in MEMa with $1 \%$ FBS $(M E M \alpha-1)$. The chromatins were harvested using Cell Signaling Technology's SimpleChIP ${ }^{\mathrm{R}}$ Enzymatic Chromatin IP Kit (Magnetic Beads) and precipitated with anti-mouse Smad4 antibody (Cell Signaling, catalog number 46535, lot 2) according to manufacturer's protocols (Cell Signaling, \#9003). Briefly, tendon fibroblasts were seeded at $2 \times 10^{6}$ per $15 \mathrm{~cm}$ plate in complete media. When the cells reached to $90-95 \%$ confluence, the media was switched to MEM $\alpha-1$. The cells were treated with TGF $\beta 1(5 \mathrm{ng} / \mathrm{ml})$ for 1 hour on the following day in $20 \mathrm{~mL}$ MEMa -1 or fresh $20 \mathrm{~mL}$ MEMa -1 for un-treated controls. At the end the stimulation, $540 \mu \mathrm{L}$ of $37 \%$ formaldehyde (Fisher Scientific, catalog number BP531) were added to cross-link the proteins with DNA. The cross-linking was stopped by adding glycine. The cells were then washed with cold PBS and pelleted in $2 \mathrm{ml}$ cold PBS at 2,000 $\mathrm{xg}$ for $5 \mathrm{~min}$. The cell pellets were then digested with $0.3 \mu \mathrm{L}$ of Micrococcal Nuclease for $20 \mathrm{~min}$ at $37^{\circ} \mathrm{C}$. The digestion was stopped by adding $10 \mu \mathrm{L}$ of $0.5 \mathrm{M}$ EDTA. The digested chromatins were then fractioned by sonication via $3 \times 30$ s pulses with $20 \%$ Duty Cycle, Output Control setting at 3 in a Branson SONIFIER 250 sonicator (Branson Ultrasonics Corp). The chromatins were then split into two parts: 1 part was saved as an input control and 1 part was incubated with anti Smad4 rabbit monoclonal antibody at 1:100 overnight at $4{ }^{\circ} \mathrm{C}$. The following day, $30 \mu \mathrm{L}$ of Protein $\mathrm{G}$ magnetic beads were added to the antibody-chromatin mix and incubated for $2 \mathrm{hr}$ at $4{ }^{\circ} \mathrm{C}$. The magnetic beads-Smad4-chromatin complexes were then purified in a DynaMag2 magnetic particle concentrator (Invitrogen). The purified complexes were eluted in a high salt solution and reverse cross-linked by proteinase $\mathrm{K}$. The immunoprecipitated chromatins and input control DNA were further purified with a DNA purification kit (Cell Signaling, catalog number 14209). The precipitated DNA was quantified using qPCR with specific primers for each potential binding site (Table 2). The binding capacity was calculated as the percentage of input using the formula: percentage of input $=2 \times 2^{\text {(Ct of input-Ct of IP) }}$. To pool data from different experiments, the fold change between TGF $\beta$ treated samples was compared to untreated samples. The conserved regulatory regions were chosen based on Pryce et al [29]. Those regions were then examined for potential Smad4 consensus binding sites using ALGGEN-PROMO [30]. 
Table 2. Primer sequences for ChIP

\begin{tabular}{|l|l|l|}
\hline Binding site & \multicolumn{1}{|c|}{ Forward primer } & \multicolumn{1}{c|}{ Reverse primer } \\
\hline$-2.5 \mathrm{~kb}$ & 5' gacctgcaggagaagaagagtg & 5' cgtaagtgtggagtcagaggtg \\
\hline$-1.2 \mathrm{~kb}$ & 5' caacctgctcatcagttagcc & 5' gcactgtgcaagacaagatgac \\
\hline$+4.9 \mathrm{~kb}$ & 5' ctgtctgcgagagaggaagc & 5' ggcagaacgaggagagagtg \\
\hline
\end{tabular}

Immunofluorescence (IF)

To examine the effectiveness of TGF $\beta$ deletion in the mouse models, cells from reporter mice were cultured and examined using immunofluorescence. After TGF $\beta$ treatment, tendon fibroblasts were washed 2 times with cold PBS and fixed in $0.4 \%$ formaldehyde (Fisher Scientific, catalog number BP531500 ) for $20 \mathrm{~min}$. The cells were then permeabilized in 1\% Triton-X100 (Sigma-Aldrich, catalog number $\mathrm{X} 100-100 \mathrm{ML}$ ) for $2 \mathrm{~min}$. After three 5 min washes with Tris Buffered Saline (Boston BioProducts, catalog number IBB-588) containing 0.5\% TWEEN®-20 (Sigma-Aldrich, catalog number P1379-100ML) (TBST), the cells were blocked with $3 \%$ bovine serum albumin (Sigma-Aldrich, catalog number A3803-100G) for 30 minutes and 1:100 anti-Smad2 (Cell Signaling Technology) for 2 hours. After 3 washes with TBST, the cells were incubated with 1:1000 Donkey anti-Rabbit IgG $(\mathrm{H}+\mathrm{L})$ Highly Cross-Adsorbed Secondary Antibody, Alexa Fluor 488 (ThermoFisher Scientific, catalog number A21206) for td-tomato positive cells or 1:1000 of Donkey anti-Rabbit IgG $(\mathrm{H}+\mathrm{L})$ Cross-Adsorbed Secondary Antibody, Alexa Fluor 555 (ThermoFisher Scientific, catalog number: A-31572) for $1 \mathrm{hr}$. The cover slips of cells were then mounted onto slides with VECTASHIELD® Antifade Mounting Media with DAPI (VECTOR Laboratories, catalog number: $\mathrm{H}-1200)$ after 5 TBST washes. Images were taken on a Nikon A1RMP Multiphoton Confocal Microscope.

\section{Statistics}

All data are presented as mean plus/minus standard deviation. The statistical significance between control and CKO groups in FACS and histology data was determined by student t-test. The statistical significance for qPCR and western blots was decided with ANOVA using Prism software (GraphPad). The micro-CT and mechanical testing data was determined by ANCOVA to correct for gender effect using SPSS 26 (IBM).

\section{Results}

TGF $\beta$ signaling was blocked in Gli1-lineage cells

To isolate Gli1-expressing cells whose TGF $\beta$ receptor 2 (TbR2) was deleted, Gli1Cre ${ }^{\text {ERT2 }}$;TbR2 ${ }^{\text {fl/fl }}$ mice were crossed to Rosa26R/mTmG reporter mice to generate Gli1Cre ${ }^{\text {ERT2 }} ; \mathrm{TbR}^{\mathrm{fl} / \mathrm{fl}} ; \mathrm{mTmG}$ mice. Tamoxifen (TAM) injection at P5 and P7 led to deletion of TbR2 and expression of GFP in Gli1-lineage cells (Figure 1A). Thus, TbR2-deleted cells expressed GFP and all other cells (that did not express Gli1) expressing td-tomato (Figure 1A). Tail-derived tendon fibroblasts (TFs) were expanded and separated based on their GFP (green fluorescence) and td-tomato (red fluorescence) expression in a flow cytometer and cultured. To test if TGF $\beta$ signaling pathway was blocked in Gli1Cre ${ }^{\text {ERT2}} ; \mathrm{TbR}^{\mathrm{fl} / \mathrm{fl}}$ cells, the sorted td-tomato+ and GFP+ cells were treated with TGF $\beta 1(5 \mathrm{ng} / \mathrm{ml})$ for 60 minutes and then stained for Smad2. In td-tomato positive (i.e., wild type) cells, Smad2 protein was primarily localized to the nuclei (Figure 1B, bottom row). In contrast, Smad2 remained in the cytoplasm of TbR2-deleted GFP+ cells (Figure 1B, top row). Consistent with this result, Western blot analysis demonstrated marked decreases in pSmad2 in TbR2deleted GFP+ cells compared to wild type cells (Figure 1C). These data demonstrate that TGF $\beta$ signaling was effectively blocked in Gli1Cre ${ }^{\mathrm{ERT} 2} ; \mathrm{TbR}^{\mathrm{fl} / \mathrm{fl}}$ tendon cells. 
A

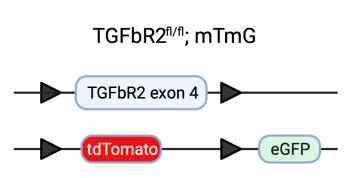

B

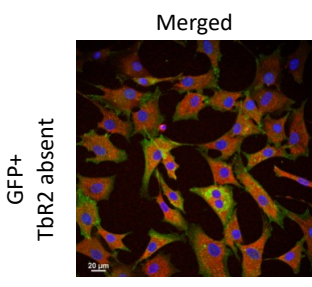

Merged

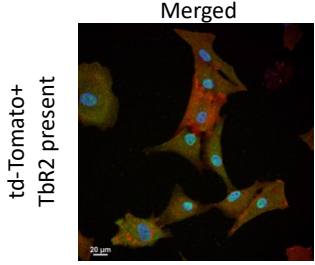

DAPI

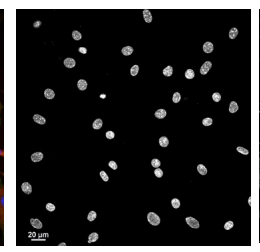

DAPI

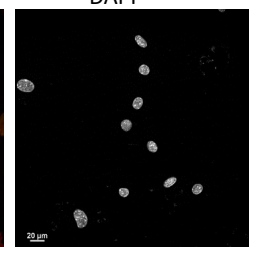

Gli1Cre ${ }^{\mathrm{ERT} 2}$

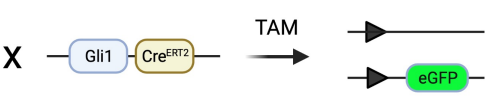

GFP

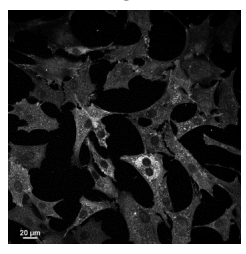

Td-tomato

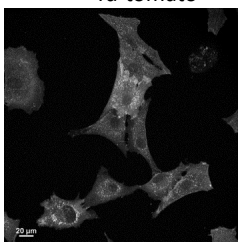

Smad2

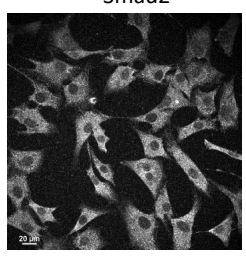

Smad2

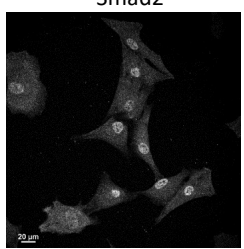

C

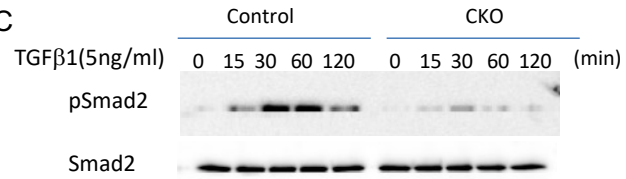

GAPDH

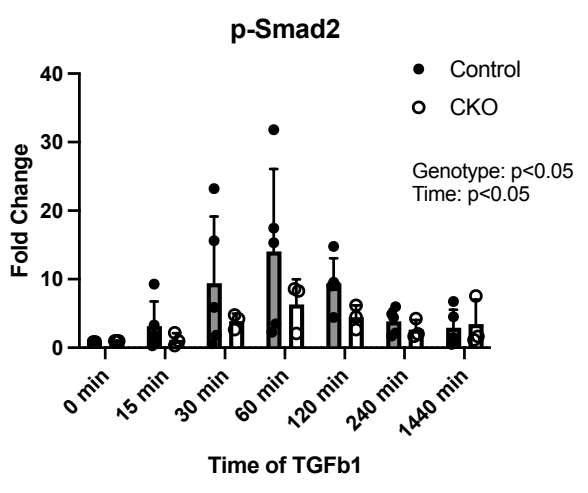

Figure 1. Generation and validation of Gli1Cre ${ }^{\mathrm{ERT}} ; \mathrm{TbR} 2^{\mathrm{fl} / \mathrm{fl}} ; \mathrm{mTmG}$ mice. (A) The strategy for generating reporter mice whose Gli1-expressing TbR2-deleted cells are tagged with GFP. (B) Immunofluorescent staining showed that TGF $\beta$-induced Smad nuclear localization was blocked in Gli1-lineage (green) cells with TbR2 deleted (top row), in contrast to wild type Gli1-lineage cells (red) (bottom row). (C) Western blot analysis demonstrated substantially reduced Smad2 phosphorylation in Gli1Cre ${ }^{\text {ERT2; TbR2 }}{ }^{\text {fl/fl }}$ cells (CKO) cells compared to control cells.

Postnatal deletion of TbR2 in Gli1-lineage cells led to mechanical and morphological defects in the enthesis

TbR2 was deleted in Gli1-lineage in the early post-natal period. Uniaxial tensile testing of supraspinatus tendon entheses revealed that the Gli1Cre ${ }^{\mathrm{ERT}} ; \mathrm{TbR2}^{\mathrm{fl} / \mathrm{fl}}(\mathrm{CKO})$ mice had lower maximum force, work to failure, and resilience compared to TbR2 ${ }^{\mathrm{fl} / \mathrm{wt}}$ control (CTRL) mice (Figure 2). MicroCT analysis of humeral head bone near the supraspinatus tendon enthesis showed that, compared to CTRL mice, CKO mice had thinner cortical bone, lower cortical bone thickness, smaller total cross-sectional area (TtAr), less bone volume to total volume ratio (BV/TV), lower bone mineral density of articular bone (trabecular BMD), and lower trabecular bone thickness (TbTh) (Figure 3). Histologic appearance of the supraspinatus tendon enthesis at P16 (i.e., immediately after enthesis mineralization) was similar in the CKO mice compared to control mice, with some decreased staining for fibrocartilage (Figure S1). 

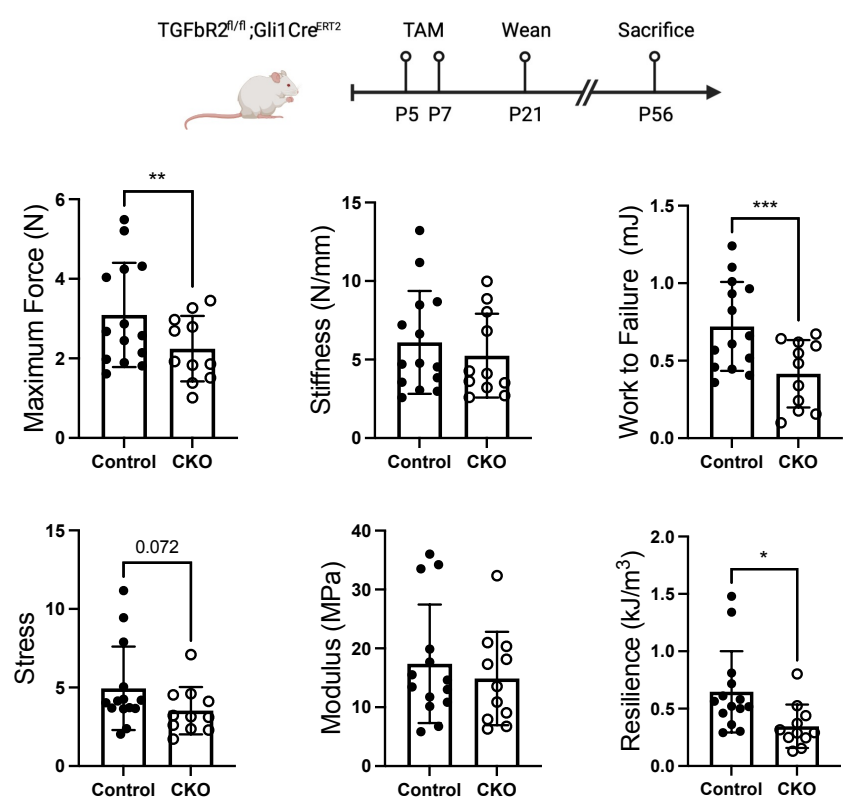

Figure 2. TbR2 deletion in Gli1-lineage cells led to reduced enthesis mechanical properties. Tamoxifen (TAM) was administrated at P5 and P7 to induce deletion of TbR2 in Gli1-expressing cells (CKO). The mechanical properties of the supraspinatus tendon enthesis were reduced in CKO mice compared to CTRL mice. ${ }^{*} p<0.05,{ }^{* *} p<0.01,{ }^{* * *} p<0.001$.

A
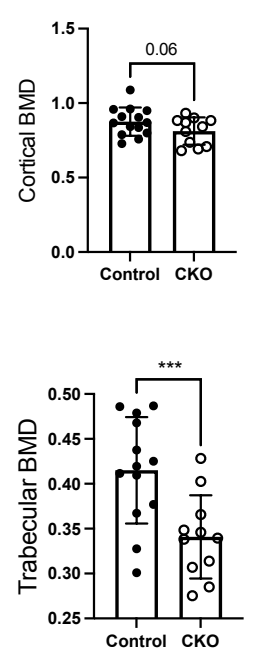
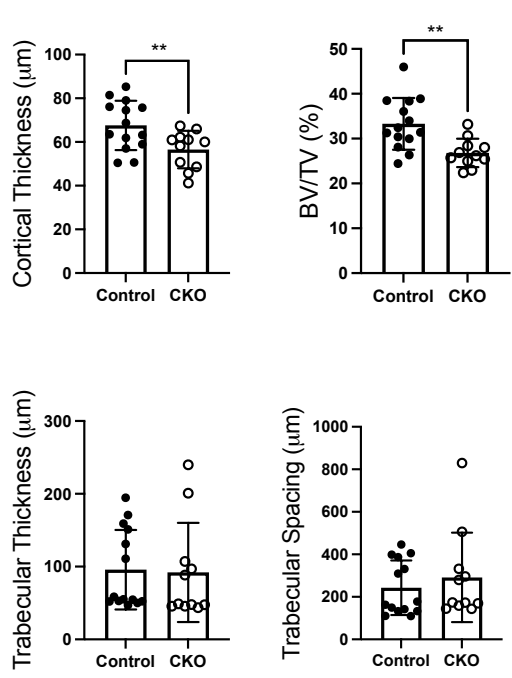

B

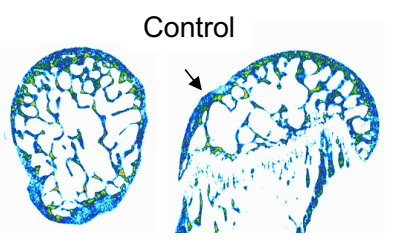

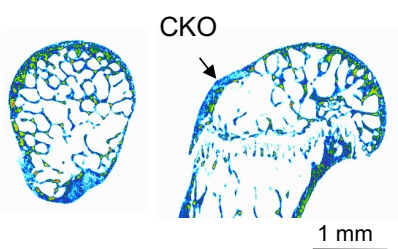

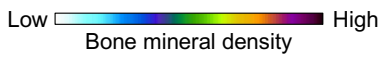

Figure 3. TbR2 deletion in Gli1-lineage cells led to altered bone morphometry adjacent to the enthesis. (A) Deletion of TbR2 in Gli1-expressing cells led to altered bone morphometry of the humeral head cortical and trabecular bone. (B) Representative microCT images show reduced trabecular bone and lower bone mineral density adjacent to the supraspinatus tendon enthesis (arrows). ${ }^{* *} \mathrm{p}<0.01,{ }^{* * *}$ $\mathrm{p}<0.001$. 
Smad-dependent canonical and Smad-independent non-canonical pathways were affected in TbR2deficient mice

FACS-sorted Gli1-lineage cells derived from tail tendon from Gli1CreERT2;TbR2 ${ }^{\text {fl/wt; }}$ mTmG control and

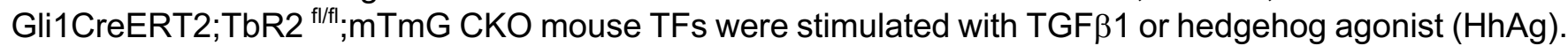
TGF $\beta$ treatment increased Scx gene expression in a time-dependent manner in control cells, and this induction was significantly reduced in CKO cells (Figure 4). Similarly, HhAg induced Scx expression in a time dependent manner, but there was no difference between responses in the control and CKO cells (Figure 4). Sox9 was not significantly induced by either TGF $\beta$ or HhAg (Figure 4). As expected TGF $\beta$ induced expression of TGF $\beta 1$ (Figure S2) and HhAg induced expression of Gli1 (Figure S3). To investigate whether Smad-dependent canonical or Smad-independent non-canonical pathways were affected by TbR2 deletion, Gli1-lineage cells were FACS sorted and stimulated with TGF $\beta$. Whole cell lysates were probed for Smad2, the key downstream signaling molecule for the canonical TGF $\beta$ pathway, as well as cJun, JNK, p38, and Erk, involved in non-canonical pathways. As expected, Smad2 phosphorylation was significantly decreased in CKO cells (Figure 1C), suggesting that the canonical pathway was affected by TbR2 deletion. Both cJun and Erk were induced by TGF $\beta$ in a time dependent manner, but only cJun and JNK activation were TbR2-dependent, showing reduced phosphorylation in CKO cells (Figure 5). Akt activation was not induced by TGF $\beta$. These results suggests that both Smad2 canonical and cJun non-canonical pathways were dependent on TbR2 in Gli1-lineage cells.
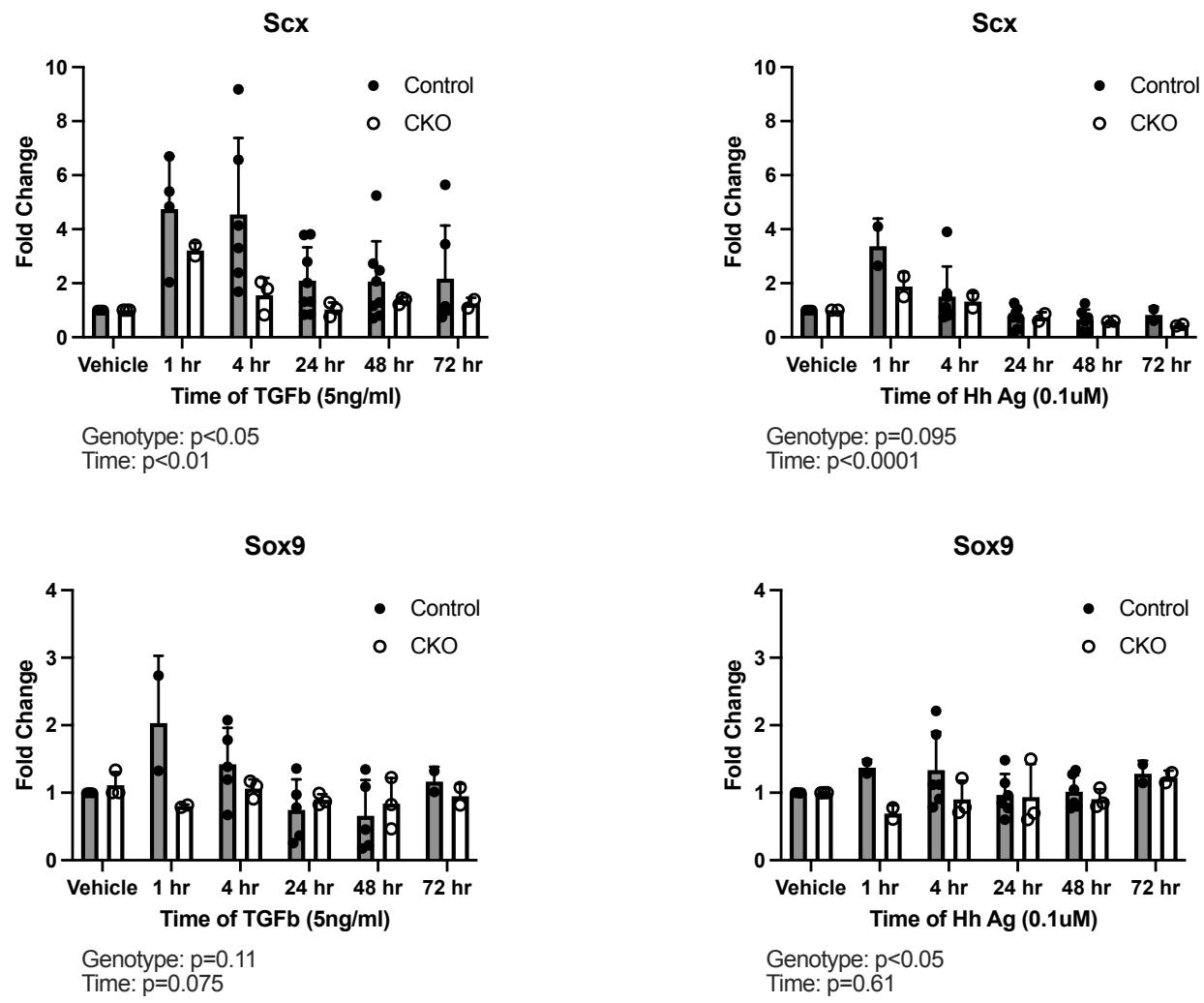

Figure 4. Responses of Gl1-lineage cells to TGF $\beta$ and HhAg in vitro. TbR2 deletion impaired TGF $\beta$ induced Scx expression and HhAg-induced Sox9 expression in Gli1-lineage cells. 
A

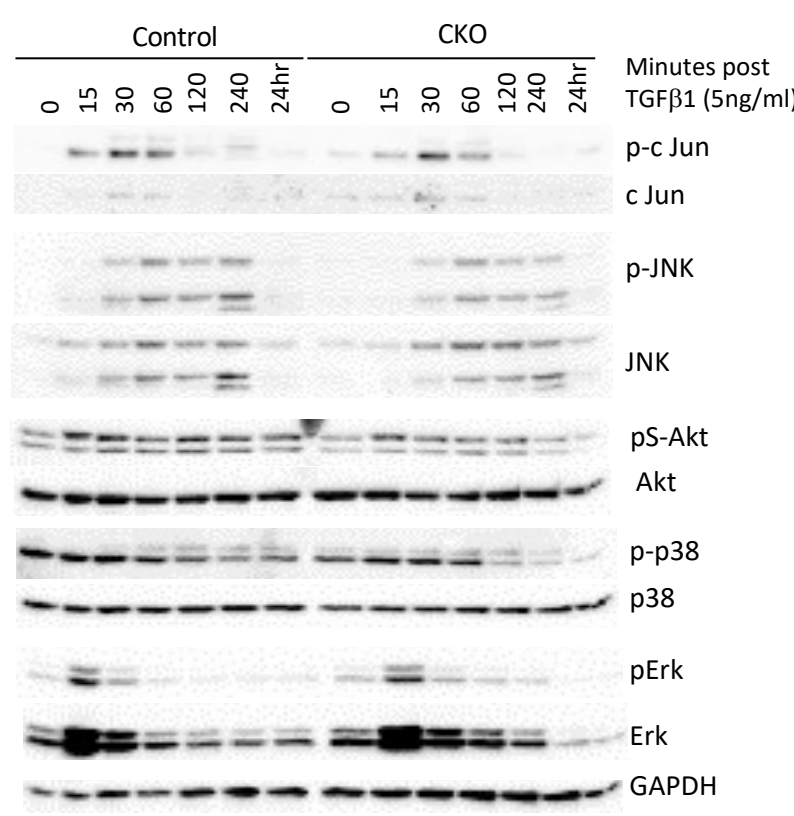

B

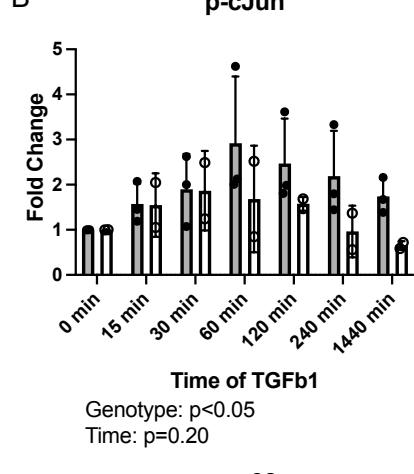

p-p38

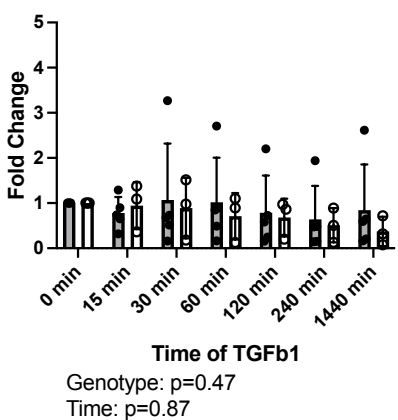

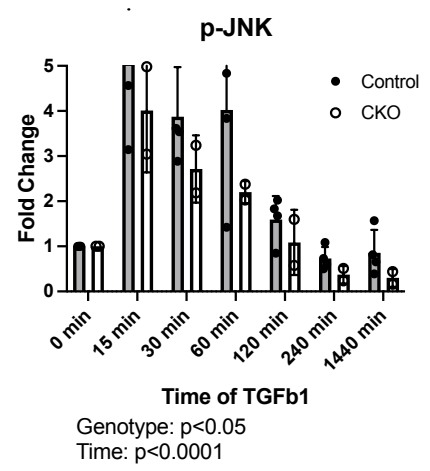

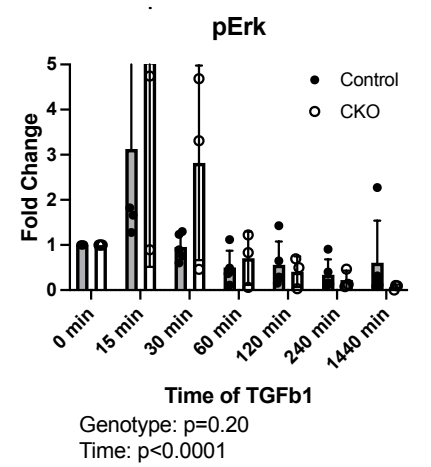

Figure 5. TGF $\beta$ induced non-canonical pathways in Gli1-lineage cells. (A) Representative western blot for control and CKO Gli1-lineage cells. (B) Quantification of phosphorylated Smad2, cJun, JNK, p38, and Erk in control and CKO Gli1-lineage cells.

\section{$\underline{\text { TbR2 CKO mice had fewer Gli1 lineage cells }}$}

Non-conical TGF $\beta$ signaling through PI3K/Akt and MAPK/JNK/cJun pathways controls cell proliferation and differentiation [31-33]. To see if TbR2 deletion in Gli1-lineage cells affected their proliferation, CTRL and CKO cells from tail tendon were cultured to passage 3 and analyzed using FACS. The number of GFP+ Gli1-lineage cells was significantly reduced in CKO mice compared to CTRL mice (Figure 6A). Similar results were seen for enthesis cells isolated from supraspinatus and infraspinatus tendon entheses (Figure S4). Consistent with these in vitro results, immunohistochemical analysis of mouse supraspinatus entheses for the proliferation marker Ki67 showed a trend of decreased Ki67+ cells in CKO entheses (Figure 6B). These data suggest that Gli1-lineage cell proliferation is in part dictated by TGF $\beta$ signaling, potentially through the MAPK/JNK/cJun pathways. 
A

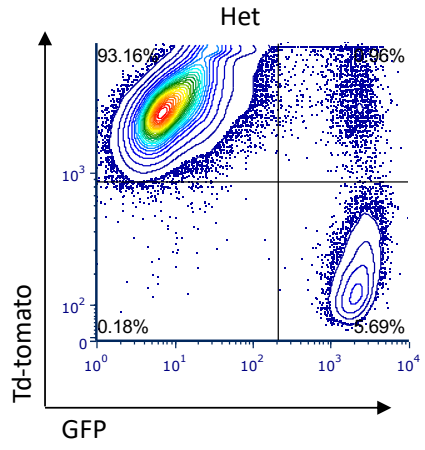

B

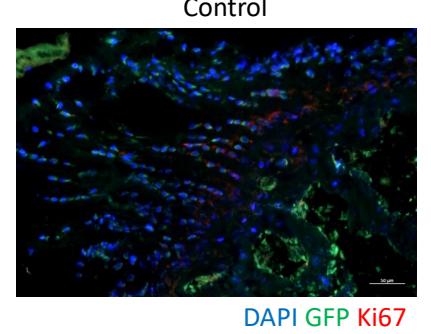

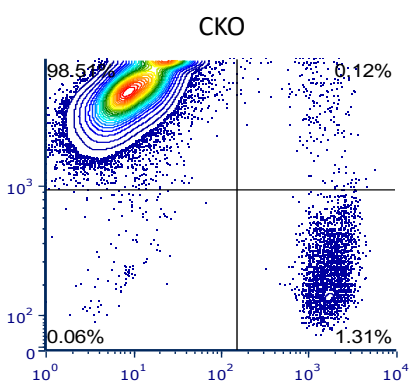

CKO

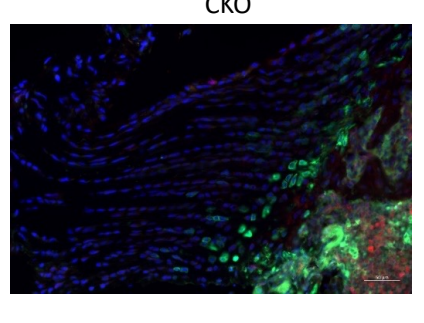

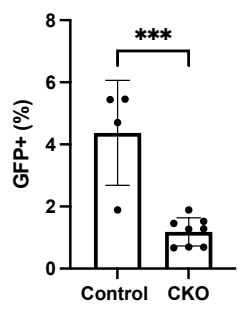

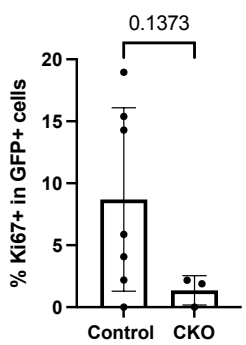

Figure 6. TbR2 deletion led to fewer Gli1-lineage cells and reduced proliferation. (A) FACS dot plots (left) and quantification (right) showed reduced numbers of Gli1-lineage cells in CKO mice. (B) Ki67 immunostaining showed decreased Ki67+ in Gli-lineage cells in CKO supraspinatus entheses (*** $\mathrm{p}<0.001)$.

TGF $\beta$ signaling drives Scx expression in Gli1-lineage cells through its distant enhancer

Previous studies have shown that TGF $\beta$ drives Scx gene expression in tendon cells [20]. However, this has not been explored in Gli1-lineage cells and the molecular mechanism by which TGF $\beta$ regulates Scx remains elusive. PROMO software was used to search 10 kilobases up- and down-stream of the mouse Scx gene, revealing three potential Smad4 binding sites (Figure 7A). Using ChIP with anti-Smad4 antibody, the strongest binding site was located $\sim 4.9 \mathrm{~kb}$ downstream of the Scx transcription starting site (Figure 7B). Binding of Smad4 to this site depended on TbR2, as TGF $\beta$-induced binding was diminished in TbR2 deficient cells (figure 7C). These data provide direct evidence that TGF $\beta$ controls Scx through Smad4 binding to the Scx enhancer $4.9 \mathrm{~kb}$ downstream from its transcription starting site. 
A

\begin{tabular}{ccc}
\multicolumn{3}{c}{ Potential Smad4 binding sites flanking mouse Scx gene } \\
\hline $\begin{array}{c}\text { Position relative to } \\
\text { transcription start }\end{array}$ & Dissimilarity & $\begin{array}{c}\text { String } \\
\text { (sequence) }\end{array}$ \\
\hline$-2.5 \mathrm{~kb}$ & 2.962 & AAGACAGACAC \\
$-1.2 \mathrm{~kb}$ & 2.956 & ATGTCTGACGT \\
$+4.9 \mathrm{~kb}$ & 3.706 & GTGTCTGTCTG \\
\hline
\end{tabular}

B

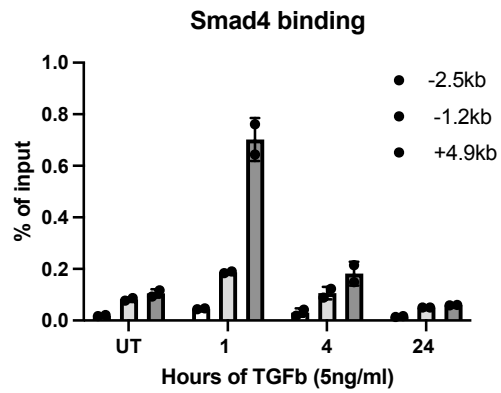

C

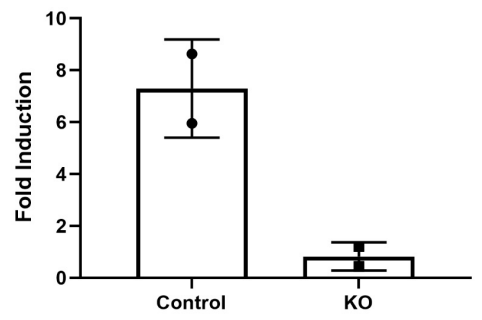

Figure 8. TGFb controls Scx expression through Smad4 binding to a distant Scx enhancer. (A) Potential Smad4 binding sites in the mouse Scx locus. (B) Time-dependent Smad4 binding to 3 potential sites. (C) Smad4 binding to $4.9 \mathrm{~kb}$ downstream of the Scx enhancer was TbR2-dependent.

\section{Discussion}

Using an inducible conditional knockout model to delete TbR2 in Gli1+ cells postnatally, the current study demonstrated a critical role of TGF $\beta$ signaling for proliferation and differentiation of this progenitor pool. The TGF $\beta$ family of growth factors have been shown to play important roles in the development, maintenance, and healing of musculoskeletal tissues, including bone, cartilage, and muscle [34, 35]. TGF $\beta$ promotes bone growth by enhancing hypertrophic chondrocyte differentiation and calcification of the bone collar through Runx2 and Wnt pathways, as well as cilia [18, 36-40]. Since the TGF $\beta$ family of ligands have been detected during tendon and enthesis development and shown to drive mesodermal stem cells differentiation into tendon lineages [41-43], we hypothesized that deletion of TbR2 in Gli1lineage enthesis cells would negatively affect development and mineralization of the enthesis. Since enthesis mineralization occurs at approximately P14 [44, 45], we induced TGFb2 deletion at P5-P7 [23]. Loss of TGF $\beta$ signaling at the postnatal enthesis led to defects in humeral head bone morphology and enthesis mechanical properties by P56. This is consistent with prior studies showing the importance of the TGF $\beta$ superfamily for tendon and enthesis development $[20,46]$.

To explore mechanisms by which TGF $\beta$ regulates enthesis cell differentiation and proliferation, a mouse reporter model was developed. The model was based on the important role that Gli1-expressing cells play in the development of a variety of tissues, including the enthesis [23]. Isolating these cells is a crucial step to understand their function and molecular mechanisms. Using Gli1Cre ${ }^{\mathrm{ERT} 2} ; \mathrm{mTmG}$ reporter mice combined with flow cytometry, we successfully isolated these cells to a high level of purity from mouse rotator cuff tendon entheses and from tail tendons. In these mice, a membrane bound td-tomato (mT) flanked a pair of loxP sequences, which was followed by a membrane enhanced GFP (mG) cloned in the R26 locus. In cells that did not contain Cre recombinase, only td-tomato was expressed. In cells that expressed Cre recombinase, the td-tomato was excised and eGFP was expressed. Therefore, 
Gli1Cre ${ }^{\text {ERT2}} ; \mathrm{TbR}^{\mathrm{fl} / \mathrm{fl}} ; \mathrm{mTmG}$ mice allowed for the isolation of GFP-expressing Gli1+ cells that had TbR2 deleted and td-tomato expressing cells that did not express Gli1 and had TbR2 intact. This tool allowed us to explore TGF $\beta$ regulation of Gli1+ cells in vitro.

At the molecular level, TGF $\beta$ signaling is initiated by binding of TGF $\beta$ superfamily growth factors such as TGF $\beta 1$ or bone morphogenetic protein (BMP) 2 to the receptor TbR2. Binding of the ligands TGF $\beta 1, \beta 2$, and $\beta 3$ leads to dimerization of TbR2 with TbR1 and downstream phosphorylation of Smad2 and 3. In contrast, binding of BMPs (e.g., BMP2, 4, 6, and 7) leads to dimerization of TbR2 with ALK1, 2, and 4, and downstream phosphorylation of Smad1, 5 and 8. Both phosphorylated Smad2/3 and phosphorylated Smad1/5/8 then further phosphorylate and combine with Smad4. Phosphorylated Smad4 brings other Smad proteins to the nucleus and binds to DNA to promote gene transcription leading to cell proliferation, differentiation, and/or extra cellular matrix (ECM) deposition $[47,48]$. Other than TGF $\beta / S m a d$ canonical signaling pathway, TGF $\beta$ also activates non-canonical pathways through TAK/MAPK and mTOR [34, 49, 50]. In the current study, canonical and non-canonical TGF $\beta$ signaling was induced by TGF $\beta 1$ in Gli1lineage cells. As expected, loss of TGF $\beta$ led to decreases in pSmad2 and a lack of Smad2 localization to cell nuclei in vitro. However, pJNK and pErk were also induced by TGF $\beta$ and deletion of TbR2 led to reduced Gli1+ cell numbers and proliferation. Therefore, it appears that TGF $\beta$ signaling is necessary for differentiation/mineralization as well as for proliferation of Gli1+ cells.

At the molecular level, TGF $\beta$ has been shown to upregulate key transcription factors for tendon and enthesis development (e.g., Scx, Mohawk) [20, 51, 52]. Furthermore, it was reported that Smad3 could physically associate with Scx and Mohawk and regulate their expression [53]. Using Gli1-expressing cells isolated from our reporter mouse model, with or without TbR2, we found that the expression of Scx was increased by TGF $\beta$ in control cells, whereas this induction was blocked in TbR2-deleted Gli1+ cells. It has been shown that Smad proteins directly associate with Scx [53]. However, the effect of this interaction is not clear. To explore how TGF $\beta$ controls Scx expression at the molecular level, we carried out a ChIP assay using an anti-Smad4 antibody, as Smad4 mediates all of the Smad protein DNA binding activities $[54,55]$. CHiP results demonstrated that Smad4 binds to the enhancer of Scx at the $+4.9 \mathrm{~kb}$ position, and this binding was significantly diminished in TbR2-deleted cells. Notably, this distal enhancer is conserved among mammals, and is thus highly likely to function similarly in other animals, including human [29]. Further mutagenesis studies are needed to prove this is the Smad4 binding site regulating activity.

The results of the current study add to the growing body of literature defining the regulation of the Gli1lineage cells that build and mineralize the enthesis. TGF $\beta$ signaling is necessary for the formation of a functional enthesis, affecting both differentiation and proliferation of Gli1-lineage enthesis cells, likely via canonical and non-canonical pathways, respectively. This work can be applied in future translational studies to drive the regeneration of the enthesis during tendon-to-bone healing via growth factor and/or stem cell therapies.

\section{Acknowledgements}

The study was supported by the NIH/NIAMS through R01AR057836. Flow cytometry analysis was supported by NIH grant S10 BR027050 and cell sorting was supported by NIH grant S10 OD020056. Microscopic core was supported by NIH grant P30 CA013696.

\section{References}

1. Degirmenci, B., T. Valenta, S. Dimitrieva, G. Hausmann, and K.J.N. Basler, GL/1-expressing mesenchymal cells form the essential Wnt-secreting niche for colon stem cells. 2018. 558(7710): p. 449-453. 
2. Brownell, I., E. Guevara, C.B. Bai, C.A. Loomis, and A.L.J.C.s.c. Joyner, Nerve-derived sonic hedgehog defines a niche for hair follicle stem cells capable of becoming epidermal stem cells. 2011. 8(5): p. 552-565.

3. Kramann, R., R.K. Schneider, D.P. DiRocco, F. Machado, S. Fleig, P.A. Bondzie, J.M. Henderson, B.L. Ebert, and B.D.J.C.s.c. Humphreys, Perivascular Gli1+ progenitors are key contributors to injury-induced organ fibrosis. 2015. 16(1): p. 51-66.

4. Kramann, R., C. Goettsch, J. Wongboonsin, H. Iwata, R.K. Schneider, C. Kuppe, N. Kaesler, M. Chang-Panesso, F.G. Machado, and S.J.C.s.c. Gratwohl, Adventitial MSC-like cells are progenitors of vascular smooth muscle cells and drive vascular calcification in chronic kidney disease. 2016. 19(5): p. 628-642.

5. Men, Y., Y. Wang, Y. Yi, D. Jing, W. Luo, B. Shen, W. Stenberg, Y. Chai, W.-P. Ge, and J.Q.J.D.C. Feng, Gli1+ periodontium stem cells are regulated by osteocytes and occlusal force. 2020. 54(5): p. 639-654. e6.

6. Zhao, H., J. Feng, K. Seidel, S. Shi, O. Klein, P. Sharpe, and Y.J.C.s.c. Chai, Secretion of shh by a neurovascular bundle niche supports mesenchymal stem cell homeostasis in the adult mouse incisor. 2014. 14(2): p. 160-173.

7. Seidel, K., C.P. Ahn, D. Lyons, A. Nee, K. Ting, I. Brownell, T. Cao, R.A. Carano, T. Curran, and M.J.D. Schober, Hedgehog signaling regulates the generation of ameloblast progenitors in the continuously growing mouse incisor. 2010. 137(22): p. 3753-3761.

8. Liu, Y., J. Feng, J. Li, H. Zhao, T.-V. Ho, and Y.J.D. Chai, An Nfic-hedgehog signaling cascade regulates tooth root development. 2015. 142(19): p. 3374-3382.

9. Schneider, R.K., A. Mullally, A. Dugourd, F. Peisker, R. Hoogenboezem, P.M. Van Strien, E.M. Bindels, D. Heckl, G. Büsche, and D.J.C.s.c. Fleck, Gli1+ mesenchymal stromal cells are a key driver of bone marrow fibrosis and an important cellular therapeutic target. 2017. 20(6): p. 785800. e8.

10. Shi, Y., G. He, W.-C. Lee, J.A. McKenzie, M.J. Silva, and F.J.N.C. Long, Gli1 identifies osteogenic progenitors for bone formation and fracture repair. 2017. 8(1): p. 1-12.

11. Fang, F. and S. Thomopoulos, Hedgehog Signaling Directs Cell Differentiation and Improves Enthesis Healing by a Cell-autonomous Mechanism, in Annual Meeting of the Orthopaedic Research Society. 2022.

12. Schwartz, A.G., F. Long, and S. Thomopoulos, Enthesis fibrocartilage cells originate from a population of Hedgehog-responsive cells modulated by the loading environment. Development, 2015. 142(1): p. 196-206.

13. Yao, L., E.D. Tichy, L. Zhong, S. Mohanty, L. Wang, E. Ai, S. Yang, F. Mourkioti, L.J.J.o.B. Qin, and M. Research, Gli1 Defines a Subset of Fibro-adipogenic Progenitors that Promote Skeletal Muscle Regeneration With Less Fat Accumulation. 2021.

14. Massague, J., TGFbeta signalling in context. Nat Rev Mol Cell Biol, 2012. 13(10): p. 616-30.

15. Bensimon-Brito, A., S. Ramkumar, G.L.M. Boezio, S. Guenther, C. Kuenne, C.S.M. Helker, H. Sanchez-Iranzo, D. lloska, J. Piesker, S. Pullamsetti, N. Mercader, D. Beis, and D.Y.R. Stainier, TGF-beta Signaling Promotes Tissue Formation during Cardiac Valve Regeneration in Adult Zebrafish. Dev Cell, 2020. 52(1): p. 9-20 e7.

16. Baffi, M.O., M.A. Moran, and R. Serra, Tgfbr2 regulates the maintenance of boundaries in the axial skeleton. Dev Biol, 2006. 296(2): p. 363-74.

17. Jin, H., J. Shen, B. Wang, M. Wang, B. Shu, and D. Chen, TGF-beta signaling plays an essential role in the growth and maintenance of intervertebral disc tissue. FEBS Lett, 2011. 585(8): p. 120915.

18. Sueyoshi, T., K. Yamamoto, and H. Akiyama, Conditional deletion of Tgfbr2 in hypertrophic chondrocytes delays terminal chondrocyte differentiation. Matrix Biol, 2012. 31(6): p. 352-9.

19. Qiu, T., X. Wu, F. Zhang, T.L. Clemens, M. Wan, and X. Cao, TGF-beta type II receptor phosphorylates $P$ TH receptor to integrate bone remodelling signalling. Nat Cell Biol, 2010. 12(3): p. 224-34. 
20. Pryce, B.A., S.S. Watson, N.D. Murchison, J.A. Staverosky, N. Dunker, and R. Schweitzer, Recruitment and maintenance of tendon progenitors by TGFbeta signaling are essential for tendon formation. Development, 2009. 136(8): p. 1351-61.

21. Tan, G.K., B.A. Pryce, A. Stabio, J.V. Brigande, C. Wang, Z. Xia, S.F. Tufa, D.R. Keene, and R. Schweitzer, Tgfbeta signaling is critical for maintenance of the tendon cell fate. Elife, 2020. 9.

22. Xu, C., X. Xie, H. Zhao, Y. Wu, J. Wang, and J.Q. Feng, TGF-Beta Receptor II Is Critical for Osteogenic Progenitor Cell Proliferation and Differentiation During Postnatal Alveolar Bone Formation. Front Physiol, 2021. 12: p. 721775.

23. Schwartz, A.G., L.M. Galatz, and S. Thomopoulos, Enthesis regeneration: a role for Gli1+ progenitor cells. Development, 2017. 144(7): p. 1159-1164.

24. Bouxsein, M.L., S.K. Boyd, B.A. Christiansen, R.E. Guldberg, K.J. Jepsen, and R. Muller, Guidelines for assessment of bone microstructure in rodents using micro-computed tomography. J Bone Miner Res, 2010. 25(7): p. 1468-86.

25. Schwartz, A.G., J.H. Lipner, J.D. Pasteris, G.M. Genin, and S. Thomopoulos, Muscle loading is necessary for the formation of a functional tendon enthesis. Bone, 2013. 55(1): p. 44-51.

26. Kurtaliaj, I., M. Golman, A.C. Abraham, and S. Thomopoulos, Biomechanical Testing of Murine Tendons. J Vis Exp, 2019(152).

27. Li, X., S. Pongkitwitoon, H. Lu, C. Lee, R. Gelberman, and S. Thomopoulos, CTGF induces tenogenic differentiation and proliferation of adipose-derived stromal cells. J Orthop Res, 2019. 37(3): p. 574-582.

28. Killian, M.L. and S. Thomopoulos, Scleraxis is required for the development of a functional tendon enthesis. FASEB J, 2016. 30(1): p. 301-11.

29. Pryce, B.A., A.E. Brent, N.D. Murchison, C.J. Tabin, and R. Schweitzer, Generation of transgenic tendon reporters, ScxGFP and ScxAP, using regulatory elements of the scleraxis gene. Dev Dyn, 2007. 236(6): p. 1677-82.

30. Messeguer, X., R. Escudero, D. Farre, O. Nunez, J. Martinez, and M.M. Alba, PROMO: detection of known transcription regulatory elements using species-tailored searches. Bioinformatics, 2002. 18(2): p. 333-4.

31. Zhao, H.F., J. Wang, and S.S. Tony To, The phosphatidylinositol 3-kinase/Akt and c-Jun Nterminal kinase signaling in cancer: Alliance or contradiction? (Review). Int J Oncol, 2015. 47(2): p. 429-36.

32. Sun, K., J. Luo, J. Guo, X. Yao, X. Jing, and F. Guo, The PI3KJKT/mTOR signaling pathway in osteoarthritis: a narrative review. Osteoarthritis Cartilage, 2020. 28(4): p. 400-409.

33. Schiaffino, S., K.A. Dyar, S. Ciciliot, B. Blaauw, and M. Sandri, Mechanisms regulating skeletal muscle growth and atrophy. FEBS J, 2013. 280(17): p. 4294-314.

34. Wu, M., G. Chen, and Y.P. Li, TGF-beta and BMP signaling in osteoblast, skeletal development, and bone formation, homeostasis and disease. Bone Res, 2016. 4: p. 16009.

35. Rahman, M.S., N. Akhtar, H.M. Jamil, R.S. Banik, and S.M. Asaduzzaman, TGF-beta/BMP signaling and other molecular events: regulation of osteoblastogenesis and bone formation. Bone Res, 2015. 3: p. 15005.

36. Seo, H.S. and R. Serra, Deletion of Tgfbr2 in Prx1-cre expressing mesenchyme results in defects in development of the long bones and joints. Dev Biol, 2007. 310(2): p. 304-16.

37. Peters, S.B., Y. Wang, and R. Serra, Tgfbr2 is required in osterix expressing cells for postnatal skeletal development. Bone, 2017. 97: p. 54-64.

38. Spagnoli, A., L. O'Rear, R.L. Chandler, F. Granero-Molto, D.P. Mortlock, A.E. Gorska, J.A. Weis, L. Longobardi, A. Chytil, K. Shimer, and H.L. Moses, TGF-beta signaling is essential for joint morphogenesis. J Cell Biol, 2007. 177(6): p. 1105-17.

39. Liu, M., M. Alharbi, D. Graves, and S. Yang, IFT80 Is Required for Fracture Healing Through Controlling the Regulation of TGF-beta Signaling in Chondrocyte Differentiation and Function. J Bone Miner Res, 2020. 35(3): p. 571-582.

40. Shen, J., J. Li, B. Wang, H. Jin, M. Wang, Y. Zhang, Y. Yang, H.J. Im, R. O'Keefe, and D. Chen, Deletion of the transforming growth factor beta receptor type /I gene in articular chondrocytes leads to a progressive osteoarthritis-like phenotype in mice. Arthritis Rheum, 2013. 65(12): p. 3107-19. 
41. Galatz, L., S. Rothermich, K. VanderPloeg, B. Petersen, L. Sandell, and S. Thomopoulos, Development of the supraspinatus tendon-to-bone insertion: localized expression of extracellular matrix and growth factor genes. J Orthop Res, 2007. 25(12): p. 1621-8.

42. Havis, E., M.A. Bonnin, I. Olivera-Martinez, N. Nazaret, M. Ruggiu, J. Weibel, C. Durand, M.J. Guerquin, C. Bonod-Bidaud, F. Ruggiero, R. Schweitzer, and D. Duprez, Transcriptomic analysis of mouse limb tendon cells during development. Development, 2014. 141(19): p. 3683-96.

43. Lorda-Diez, C.I., J.A. Montero, C. Martinez-Cue, J.A. Garcia-Porrero, and J.M. Hurle, Transforming growth factors beta coordinate cartilage and tendon differentiation in the developing limb mesenchyme. J Biol Chem, 2009. 284(43): p. 29988-96.

44. Zelzer, E., E. Blitz, M.L. Killian, and S. Thomopoulos, Tendon-to-bone attachment: from development to maturity. Birth Defects Res C Embryo Today, 2014. 102(1): p. 101-12.

45. Schwartz, A.G., J.D. Pasteris, G.M. Genin, T.L. Daulton, and S. Thomopoulos, Mineral distributions at the developing tendon enthesis. PLoS One, 2012. 7(11): p. e48630.

46. Blitz, E., S. Viukov, A. Sharir, Y. Shwartz, J.L. Galloway, B.A. Pryce, R.L. Johnson, C.J. Tabin, R. Schweitzer, and E. Zelzer, Bone ridge patterning during musculoskeletal assembly is mediated through SCX regulation of Bmp4 at the tendon-skeleton junction. Dev Cell, 2009. 17(6): p. 86173.

47. Massague, J., TGFbeta in Cancer. Cell, 2008. 134(2): p. 215-30.

48. Feng, X.H. and R. Derynck, Specificity and versatility in tgf-beta signaling through Smads. Annu Rev Cell Dev Biol, 2005. 21: p. 659-93.

49. Moustakas, A. and C.H. Heldin, The regulation of TGFbeta signal transduction. Development, 2009. 136(22): p. 3699-714.

50. Choi, M.E., Y. Ding, and S.I. Kim, TGF-beta signaling via TAK1 pathway: role in kidney fibrosis. Semin Nephrol, 2012. 32(3): p. 244-52.

51. Farhat, Y.M., A.A. Al-Maliki, T. Chen, S.C. Juneja, E.M. Schwarz, R.J. O'Keefe, and H.A. Awad, Gene expression analysis of the pleiotropic effects of TGF-beta1 in an in vitro model of flexor tendon healing. PLoS One, 2012. 7(12): p. e51411.

52. Sakabe, T., K. Sakai, T. Maeda, A. Sunaga, N. Furuta, R. Schweitzer, T. Sasaki, and T. Sakai, Transcription factor scleraxis vitally contributes to progenitor lineage direction in wound healing of adult tendon in mice. J Biol Chem, 2018. 293(16): p. 5766-5780.

53. Berthet, E., C. Chen, K. Butcher, R.A. Schneider, T. Alliston, and M. Amirtharajah, Smad3 binds Scleraxis and Mohawk and regulates tendon matrix organization. J Orthop Res, 2013. 31(9): p. 1475-83.

54. Kretzschmar, M. and J. Massague, SMADs: mediators and regulators of TGF-beta signaling. Curr Opin Genet Dev, 1998. 8(1): p. 103-11.

55. Massague, J., TGF-beta signal transduction. Annu Rev Biochem, 1998. 67: p. 753-91. 


\section{Control}

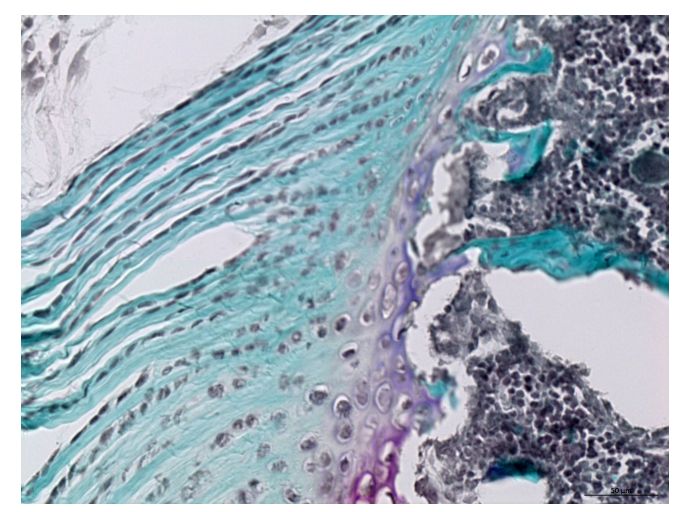

CKO

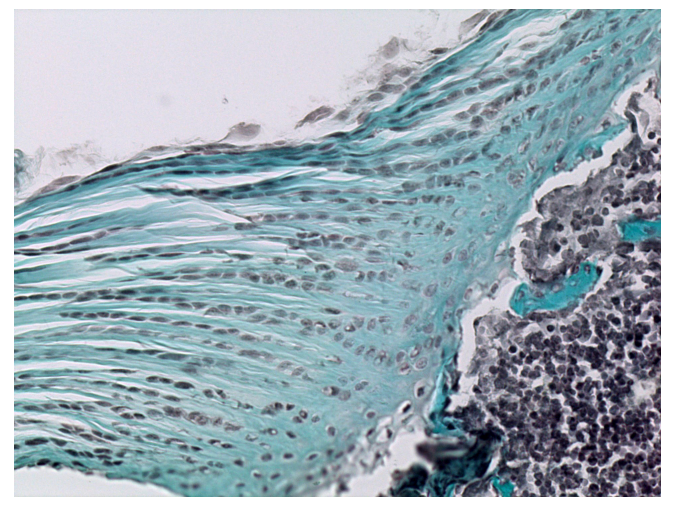

Figure S1. Representative histologic sections for control and CKO supraspinatus tendon entheses (Safranan O stain).
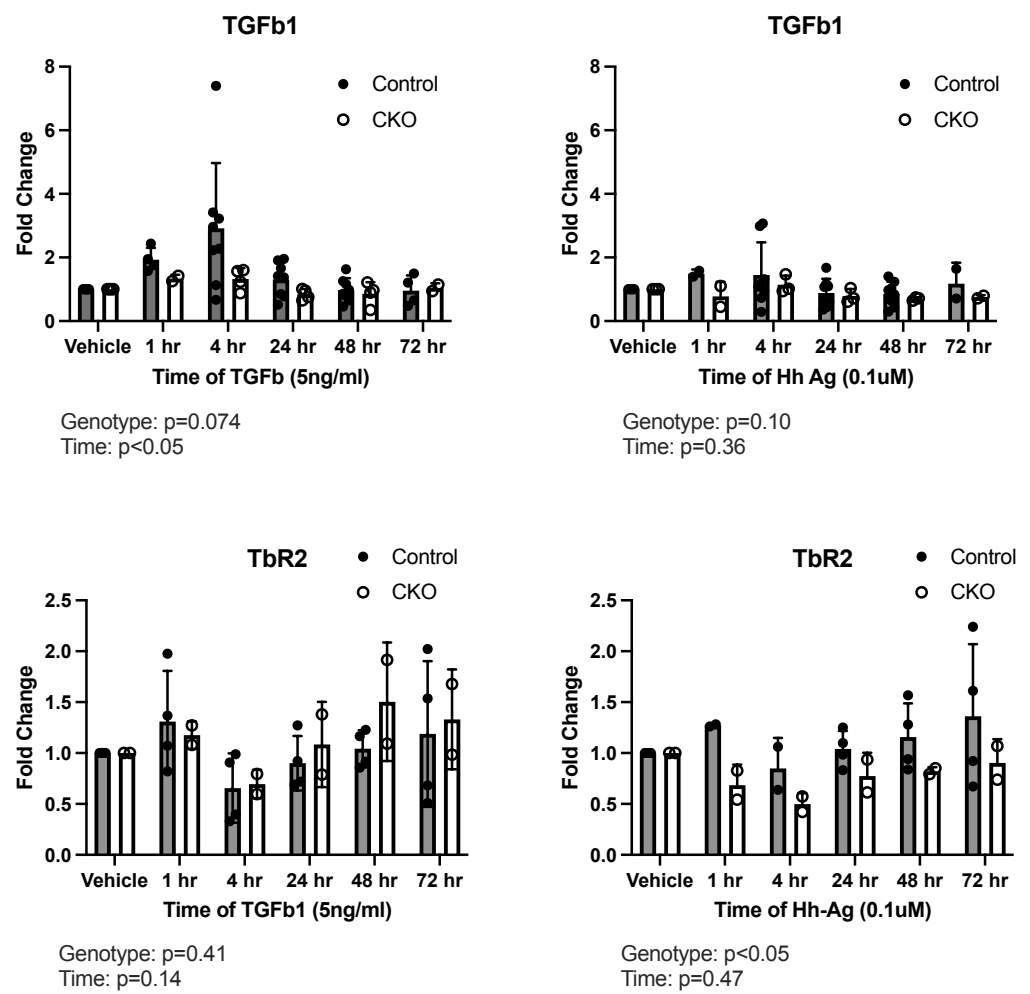

Figure S2. TGF $\beta$-related responses of Gl1-lineage cells to TGF $\beta$ and $\mathrm{HhAg}$ in vitro. 
Gli1

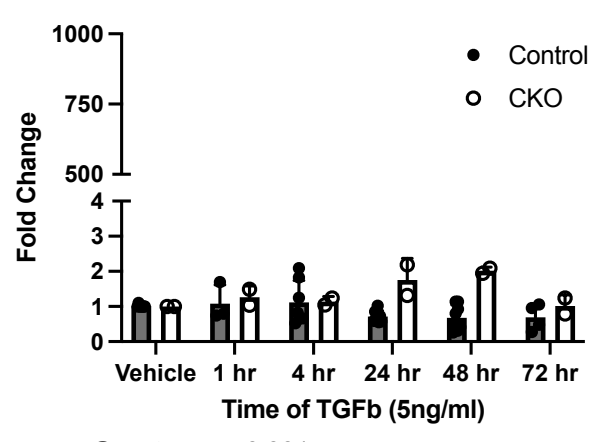

Genotype: $p<0.001$

Time: $p=0.27$
Gli1

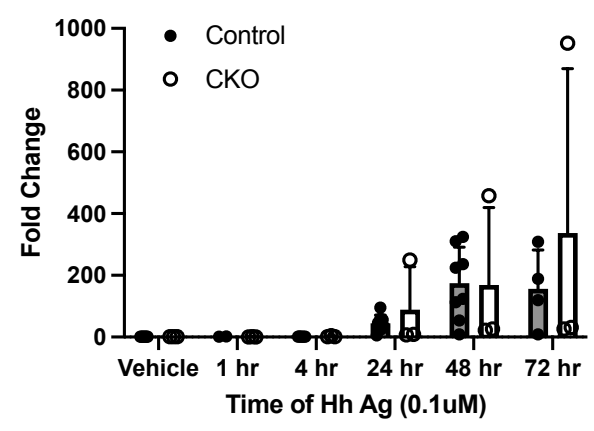

Genotype: $p=0.41$

Time: $p<0.01$

Figure S3. Hedgehog-related responses of Gl1-lineage cells to TGF $\beta$ and HhAg in vitro.

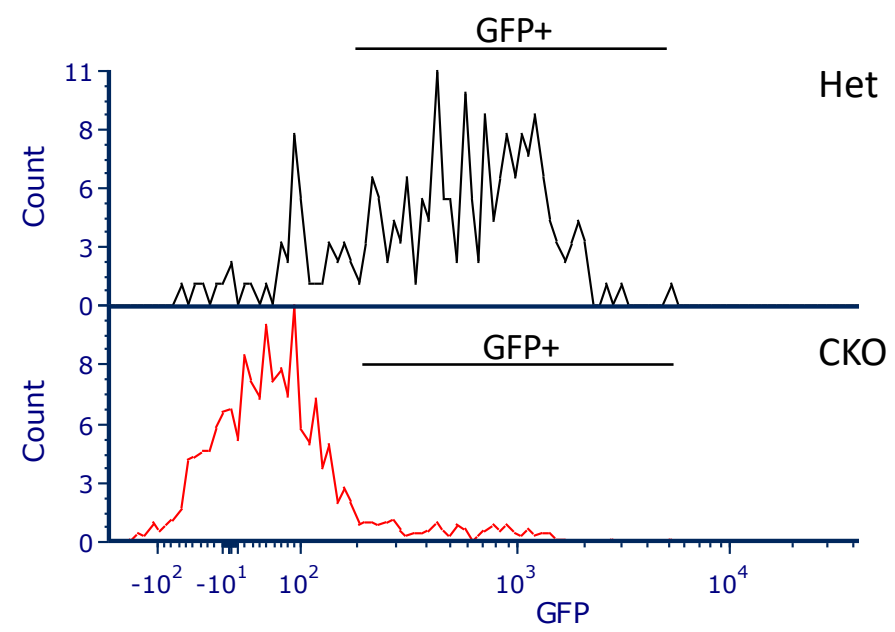

Figure S4. Histogram showing there were fewer GFP+ lineage cells in TGFbRII CKO entheses compared to control entheses. The data are representative of two independent experiments. 